1475 Mikt TRACHEal aspirate LUNG PROFILE. Randy Randel, Mikko Hallman, Marie Kulovich, Roy Caviglia, Louis Gluck. Univ. of Calif., San Diego, Dept. of Ped. La Jolla, Calif.

The lecithin/sphingomyel in (L/S) ratio \& percent phosphatidy glycerol (PG) in amniotic fluid are used to evaluate fetal lung maturity, but their value in tracheal aspirates to predict respiratory distress syndrome (RDS) has not been defined. Phospholipid lung profiles on tracheal aspirates within 12 hrs of birth from 551 babies were analyzed by 2 -dimensional thin layer chrom atography \& reflectance densitometry.

infants with respiration, asphyxia, pneumonia, syndromes,

chorioamionitis, IUGR, or pulmonary hypoplasia were excluded.

Radiologic \& clinical criteria were used to classify the remaining patients as RDS (125), retained lung fluid (RLF) (50), or no respiratory disease $(60)$. L/S best predicted RDS ( $78 \%$ ) when
values were $\leq 2.6$ \& identified normals $(85 \%)$ above 2.6 . The mean $L / S$ for RLF (4.06) \& normals (4.37) were higher than for RDS (2.3). Accuracy of $P G$ in predicting RDS was best $(96 \%)$ at trace $(<1 \%)$ or less, identifying $83 \%$ of normals. Seventeen percent of normals $\& 56 \%$ of RLF had $<1 \%$ PG, while $4 \%$ of RDS cases had $>1 \%$ PG. Lung profile values accepted for amniotic fluid seem to overestimate pulmonary maturity when applied to tracheal aspirates. Tracheal aspirate L/S \& PG together are highly useful in the biochemical diagnosis of RDS. ing patients as RDS (125), retained lung fluid (RLF) (50), or
no respiratory disease (60). L/S best predicted RDS (78\%) when

1478

THE EFFECTS OF CHORIOAMNIONITIS ON THE NEONATE. Ctr., Jackson, MS.

Increased neonatal prematurity, morbidity, and mortality is reported to be associated with chorioamnionitis(chorio). The present study was designed to determine the effects of chorio on the incidence of neonatal bacterial infections, hyaline membrane disease(HMD), asphyxia, and mortality. The charts of mothers with chorio and their infants were reviewed retrospec tively from Jan 1980-Dec 1982. Maternal chorio was defined as fever $>100.4$, tender lower abdomen, and/or leukocytosis $>20,000$. The control for each study patient was defined as the next live born infant with a birthweight (BW) within $100 \mathrm{gm}$. In the study population $71 \%$ of the infants had a BW of $<2500 \mathrm{gm}$. Bacterial infection, $H M D$, and mortality were not significantly different in the study and control groups. However, the incidence of asphyxia was significantly higher in the study group ( $p$ value

\begin{tabular}{|c|c|c|c|c|c|}
\hline & $\frac{\text { Number of }}{\text { Patients }}$ & $\frac{\text { Bacterial }}{\text { Infection }}$ & $\mathrm{HMD}$ & Asphyxia & Deaths \\
\hline Study & 116 & 11 & 33 & $\begin{array}{l}1 \text { min } \leq 5 \\
5 \text { min } \leq 6\end{array}$ & 23 \\
\hline Control & 116 & 9 & 31 & $\begin{array}{l}31 \\
18\end{array}$ & 13 \\
\hline P value & & $<.75$ (NS) & $<.9(\mathrm{NS})$ & $<.025(\mathrm{~S})$ & $<. l(\mathrm{NS})$ \\
\hline
\end{tabular}

From this data it appears that maternal chorio is significantly associated with asphyxia in the neonate but not directly with neonatal infection.

PRENATAL CARE AND PREMATURITY. James S. Rawlings,

1476 Franklin R. Smith, Roger A. Spencer. Tripler Army The value of frequent, Dept of Pediatrics, Honolulu, HI seemingly uncomplicated proutine prenatal clinic visits in determine whether routine outpatient care significantly influ ences the incidence of premature delivery, we analyzed prenatal one-year period. atnong low-risk patients who delivered over one-year period. Prenatal care records of 50 patients who delivered prematurely were compared to those of 175 randomly selected patients who delivered at term. There were no demographic differences between the two groups. Rates of clinic attendance were significantly lower $(p<0.01)$ among patients who delivered severely premature infants (Table). Mortality among premature infants with a history of poor prenatal care was $23 \%$ in contrast to $2 \%$ mong prematures with natal care $(p<0.001)$. We conclude that seemingly low-risk obstetric patients who demonstrate poor early prenatal care compliance are at high risk for premature delivery and neonatal demise. Routine prenatal care may be an important factor in limiting both the incidence and degree of prematurity. PERCENT COMPLIANCE, WITH PRENATAL CARE GUIDELINES RECOMMENDED GESTATIONAL AGE AT DELIVERY VISIT DATES $\frac{\text { G }}{25-30 \text { WKS } 31-35 \text { WKS } 37-43}$ WKS

$\begin{array}{ccccl}\begin{array}{c}\text { ISIT DATES } \\ \text { (WEEKS) }\end{array} & \begin{array}{c}25-30 \text { WKS } \\ (\mathrm{N}=12)\end{array} & \begin{array}{c}31-35 \text { WKS } \\ (\mathrm{N}=38)\end{array} & \begin{array}{c}37-43 \\ (\mathrm{~N}=175)\end{array} & \begin{array}{l}\text { ( } \mathrm{p}<0.01 \\ \text { when }\end{array} \\ 8-12 & 0 \% * & 29 \% * & 56 \% & \text { compared } \\ 13-16 & 25 \% * & 58 \% & 67 \% & \text { to term } \\ 17-20 & 42 \% * & 63 \% & 76 \% & \text { deliveries }) \\ 21-24 & 50 \% * & 79 \% & 82 \% & \end{array}$

177 DIAGNOSIS OF PATENT DUCTUS ARTERIOSUS IN VLBW INFANTS

1477 BY PRECORDIAL CONTRAST ECHOCARDIOGRAPHY(CE). Philip G. Rhodes, Mitzi G. Ferguson, James A. Joransen . Matel (Spon. B. Batson), Dept. of Peds. U, of Miss. Med , Jackson, MS.

Patent ductus arteriosus(PDA) is an important negative factor in the clinical course of the VLBW infant with hyaline membrane disease (HMD). This study was designed to diagnose the PDA by CE and to close the PDA with oral indomethacin. In 78 VLBW infants with an umbilical artery catheter, the patency of the ductus arteriosus was determined by $C E$ within the 1 st $72 \mathrm{hrs}$ of life. If the $C E$ was positive for a PDA, indomethacin was adminstered in 2 doses of $0.15 \mathrm{mg} / \mathrm{kg}$ OG $12 \mathrm{hrs}$ apart. A 2 nd $\mathrm{CE}$ was done follow ing the 2 nd dose to determine closure of the PDA. Results are:

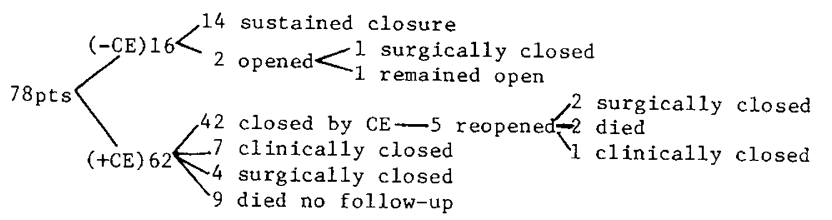

The PDA can be determined simply by $C E$ and oral indomethacin is effective in closing the PDA in most VLBW infants $<72 \mathrm{hrs}$ of age with $\mathrm{HMD}$.

1. Zednikova, M., et al, Ped. Cardiol, Vol. 2, 1982
1479 TERM NEONATES. Karen E. Shattuck, C. Joan

Rassin), Univ. of Texas $\frac{\text { Richardson, }}{\text { Medical Branch, Departments of Pediatrics }}$ and Radiology, Galveston, Texas.

Cerebral ultrasonography was done within 72 hours of birth on 505 newborns of $\geq 37$ weeks gestation admitted during an 8 week period to the normal newborn nursery. Abnormalities were detected in 23 babies $(4.6 \%)$. Bilateral SEH occurred in $14(2.8 \%)$ and unilateral SEH in $6(1,2 \%)$. Agenesis of the corpus callosum was detected in $2(0,4 \%)$ and mild ventricular dilatation in 1 $(0.2 \%)$. None of the 20 babies with SEH had intraventricular $(0.2 \%)$. None of the 20 babies with SEH had intraventricular
hemorrhage. When compared to babies with no SEH, those with SEH were of significantly lower gestational age and birth weight. The difference in weight was attributable to lower birth weights in females with SEH compared to females without SEH. Signifidelivered vaginally, and were black. No differences existed between babies with and without SEH in regard to gender, obstetrical presentation, use of forceps, birth trauma, Apgar scores, asphyxia, maternal age and parity, and clinical baby, this study indicates that $\mathrm{SEH}$ is relatively common $(4.0 \%)$ in the term newborn and may be clinically silent. In this
study babies at greatest risk for SEH were black, small for gestational age, and vaginally delivered。

\section{SUBEPENDYMAL GERMINAL MATRIX HEMORRHAGE (SEH) IN} cantly more babies with SEH were small for gestational age, were problems. Although SEH is primarily a problem of the premature
180 NUCHAL CORD (NC) AS a CAUSE OF NEONATAL ANEMIA.

1480 Angela J. Shepherd and $\mathrm{C}$. Joan Richardson (Spon。 by Department of Pediatrics, Galveston, Texas.

Although NC occurs in $20 \%$ of deliveries and may be associated with perinatal asphyxia, anemia has not been emphasized as a complication of NC. We documented the occurrence of NC in 437 consecutive births and compared the incidence of anemia (venous hemoglobin $<13.2 \mathrm{mg} / \mathrm{dl}$ or hematocrit $<39.17 \%$ ) in the group with NC to a group of 49 normal controls derfved from the same population. NC occurred in $86(19.7 \%)$. Tight NC (TNC), defined as nonreducible and clamped early, occurred in $39(8.9 \%)$. Loose NC (LNC), defined as reducible, occurred in $47(10.8 \%)$. None of the controls were anemic. Of 27 babies studied who had TNC, 5 $(18.5 \%)$ were anemic $(p<0.01)$ early $(<8$ hours of age). Three of the 5 were hypotensive and anemic at birth and required blood transfusion. of 30 babies studied who had LNC, $4(13.3 \%)$ were anemic $(\mathrm{p}<0.05)$. None of the 4 were anemic early, but were anemic $(p<0.05)$. None of the 4 were anemic early, but were
anemic by 36 hours of age. These data suggest: 1) TNC and LNC anemic by 36 hours of age. These data suggest: 1) TNC and LNC
are associated with increased risk of anemia, 2) Anemia due to 3) Anemia due to LNC is not present at birth but occurs ( $>24$ hours). 4) Babies with NC should have hemoglobin/hematocrit determinations soon after birth, if symptomatic, or before discharge, if asymptomatic. TNC is present at or soon after birth and may require transfusion. 